\title{
The Extratropical Transition of Tropical Cyclone Lili (1996) and Its Crucial Contribution to a Moderate Extratropical Development
}

\author{
Anna Agustí-Panareda And SuZanne L. Gray \\ Department of Meteorology, University of Reading, Reading, United Kingdom \\ George C. Craig \\ DLR-Institut fuer Physik der Atmosphaere, Wessling, Germany \\ Chris Thorncroft \\ The University at Albany, State University of New York, Albany, New York
}

(Manuscript received 5 March 2004, in final form 16 November 2004)

\begin{abstract}
The transition that a tropical cyclone experiences as it moves into the extratropical environment (known as extratropical transition) can result in the decay or intensification of a baroclinic cyclone. The extratropical transition (ET) of Tropical Cyclone Lili (1996) in the North Atlantic resulted in a moderate extratropical development of a baroclinic cyclone. The impact of Lili in the extratropical development that occurred during its ET is investigated. Numerical experiments are performed using potential vorticity inversion and the Met Office Unified Model to forecast the extratropical development with and without the tropical cyclone in the initial conditions. In contrast with other case studies in the literature, Lili is shown to play a crucial role during its ET in the development of a baroclinic cyclone that occurred in the same region. A hypothesis of the possible scenarios of ET is presented that links the case-to-case variability of ET case studies in the literature with a classification of the life cycles of baroclinic cyclones.
\end{abstract}

\section{Introduction}

The study of the extratropical transition (ET) of tropical cyclones provides a challenge for both the research and forecasting communities (Jones et al. 2003). It has been mostly studied by analysis of different case studies in the northwest Pacific (e.g., Matano and Sekioka 1971; Harr and Elsberry 2000; Klein et al. 2000), southwest Pacific (e.g., Sinclair 1993, 2002), southeast Indian Ocean (e.g., Foley and Hanstrum 1994), and North Atlantic (e.g., DiMego and Bosart 1982a,b; Bosart and Lackmann 1995; Thorncroft and Jones 2000). Extratropical transitions are common events, as shown by the various climatologies of the different basins where tropical cyclones recurve (see

Corresponding author address: Anna Agustí-Panareda, Department of Meteorology, Earley Gate, P.O. Box 243, Reading RG6 6BB, United Kingdom.

E-mail: A.Agusti-Panareda@reading.ac.uk
Klein et al. 2000; Hart and Evans 2001; Sinclair 2002; Foley and Hanstrum 1994; Jones et al. 2003).

Extratropical transitions can have a large destructive impact (Jones et al. 2003) because they can result in large and deep extratropical cyclones. However, there is a large case-to-case variability in the outcome of ETs (Evans and Hart 2003). After a transformation period during which the tropical cyclone loses its convective core and develops a frontal structure (Klein et al. 2000), the cyclone undergoes an extratropical stage during which it can either intensify as an extratropical cyclone or decay. For example, Iris (1995) (Thorncroft and Jones 2000), Earl (1998) (McTaggart-Cowan et al. 2001), and Irene (1999) (Agustí-Panareda et al. 2004) all resulted in explosive intensifications (i.e., the minimum mean sea level pressure deepened $24 \mathrm{mb}$ or more in $24 \mathrm{~h}$ ); Lili (1996) (Browning et al. 1998) resulted in a moderate intensification ( $9 \mathrm{mb}$ in $24 \mathrm{~h}$ ); and Felix (1995) (Thorncroft and Jones 2000) experienced a decay after the transformation stage. The reason for the large case-to-case variability of ETs is still not well un- 
derstood. Hart and Evans (2001) suggest that the time in which the transitioning storm is in an environment that supports neither tropical nor extratropical development as well as whether the tropical cyclone has been formed in the deep Tropics are likely to be important factors in determining the outcome of the intentensification during an ET. In addition, several hypotheses have been presented regarding the case-to-case variability of intensification associated with an ET. These are based on factors such as the variability of largescale extratropical patterns (Harr and Elsberry 2000), the phasing between the tropical cyclone and the extratropical forcing (Klein et al. 2002), and the presence of the tropical cyclone (Ritchie and Elsberry 2003). In this paper we explain why Lili (1996) had a crucial role in the moderate reintensification that resulted from its ET and relate this to the environmental barotropic shear that is known to determine the nature of the life cycles of baroclinic cyclones (see Shapiro et al. 1999 for a review).

Klein et al. (2000) suggested that the character of the midlatitude circulation (e.g., a trough) plays a more important role in the ET than the characteristics of the tropical cyclone before ET (e.g., the intensity of a tropical cyclone). Indeed, studies by McTaggart-Cowan et al. (2001) and Agustí-Panareda et al. (2004) on the case studies of Earl (1998) and Irene (1999), respectively, found that the role of the tropical cyclone in the ET process was secondary. On the other hand, idealized simulations by Ritchie and Elsberry (2003) suggest that the remnants of a tropical cyclone can play a primary role in the ET when they interact with a weak midlatitude upper-level trough. A strong intensification of the remnants of the tropical cyclone occurred, but the development was insignificant when the tropical cyclone was not present in the simulation. However, the results shown by Ritchie and Elsberry (2003) have not yet been reported for any analyzed case study. The case study of the ET of Lili (1996) presented here is the first for which it is shown that the extratropical development would not have occurred without the tropical cyclone. To investigate the role that Lili played in the ET, the tropical cyclone has been removed from the initial conditions of the numerical forecast as in Agustí-Panareda et al. (2004).

Lili (1996) experienced ET in the middle of the North Atlantic and underwent a moderate intensification $(10 \mathrm{hPa}$ in $24 \mathrm{~h}$ ) just before it crossed the British Isles as a mature extratropical cyclone. The ET of Lili (1996) is very well documented by Carroll (1997) and Browning et al. (1998, 2000). An overview of the ET of Lili (1996) is given in section 2. The numerical model used to perform the numerical experiments is briefly described in section 3, as well as the method used to remove the tropical cyclone from the initial conditions. The results of the numerical experiments are shown in section 4. Section 5 contains the discussion of the numerical results and the suggestion of a hypothesis that links the role of the tropical cyclone in the ET event with the baroclinic life cycle that characterizes the extratropical development without the tropical cyclone. Finally, a brief summary is given in section 6 .

\section{Synoptic overview}

Hurricane Lili started to weaken to tropical storm strength as it moved over cooler sea surface temperatures (SSTs) (Lawrence 1996). The ET of Lili (1996) started as the tropical cyclone interacted with the trailing cold front of a primary cyclone downstream (see Fig. 1a) and developed a warm front to the north (Fig. 1b). At that time Lili had approached a favorable region for development to the right entrance of the jet streak (Fig. 1b). By 0000 UTC on 27 October, deep convective cloud was observed to be displaced to the north of Lili's low pressure center in infrared (not shown) and water vapor satellite images (Carroll 1997). This was collocated with a strong low-level potential temperature gradient (Fig. 1c).

The National Hurricane Center classified Lili as extratropical at 0600 UTC 27 October. At that time, Lili had lost its deep convective core and exhibited an asymmetric extratropical structure with an extensive cloud band along its warm front (not shown). During this transformation period, the cyclone's minimum mean sea level pressure (MSLP) did not change significantly, fluctuating mainly within $\pm 3 \mathrm{hPa}$ of $979 \mathrm{hPa}$ between 1200 UTC on the 21st and 1200 UTC on the 27th according to the Met Office analyses (Browning et al. 1998). From 1200 UTC on the 27th to 0600 UTC on the 28th the cyclone deepened by approximately $10 \mathrm{hPa}$ (Browning et al. 1998). The lowest minimum MSLP was $970 \mathrm{hPa}$ at $0600 \mathrm{UTC}$ on the 28th when the cyclone started to cross Ireland (Browning et al. 1998).

A trough disruption occurred at the same time as the cyclone started to intensify. Trough Tr in Fig. 1d elongated with a southwest-northeast tilt and eventually produced a cutoff with high potential vorticity (PV) (Figs. 1e and 1f). The trough disruption can also be observed in water vapor images (Carroll 1997). The peak deepening was linked to the interaction between two major dry intrusions of stratospheric and uppertropospheric air associated with two separate tropopause depressions and the strong low-level circulation of the transformed surface cyclone (see Browning et al. 1998, 2000). The first tropopause depression (D1) approached Lili from the west and started to merge with 
(a)

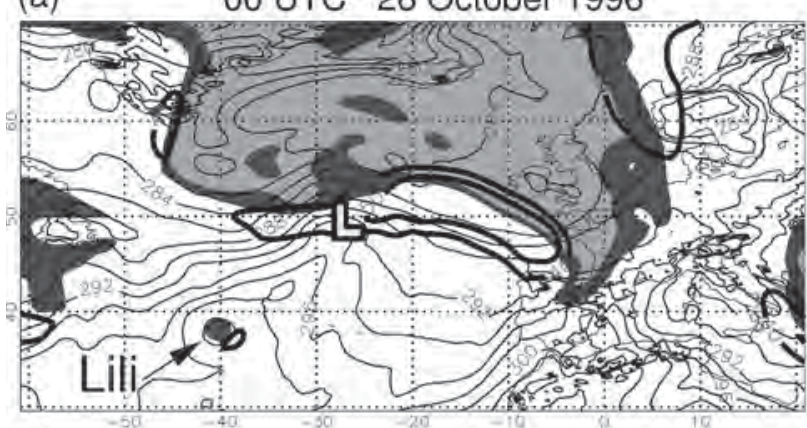

(c)

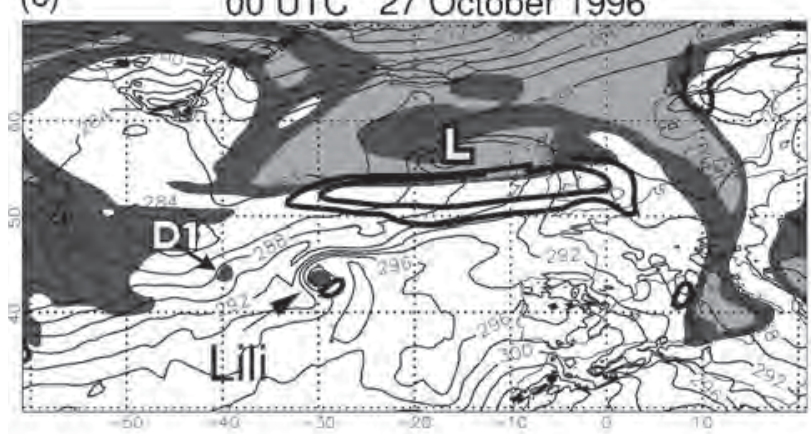

(e)

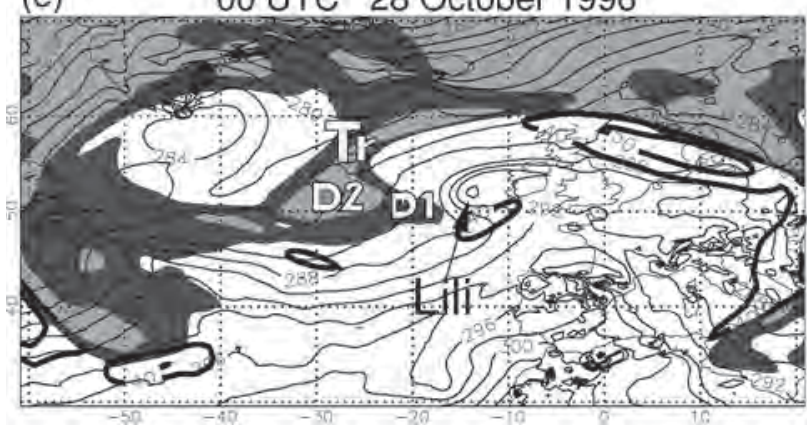

(b)

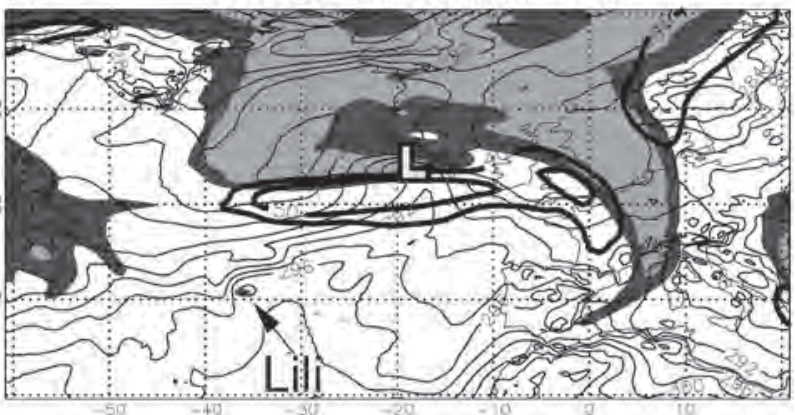

(d)

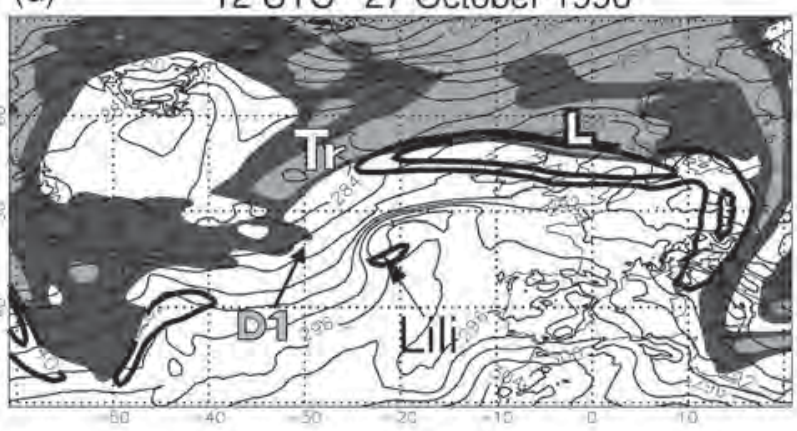

(f)

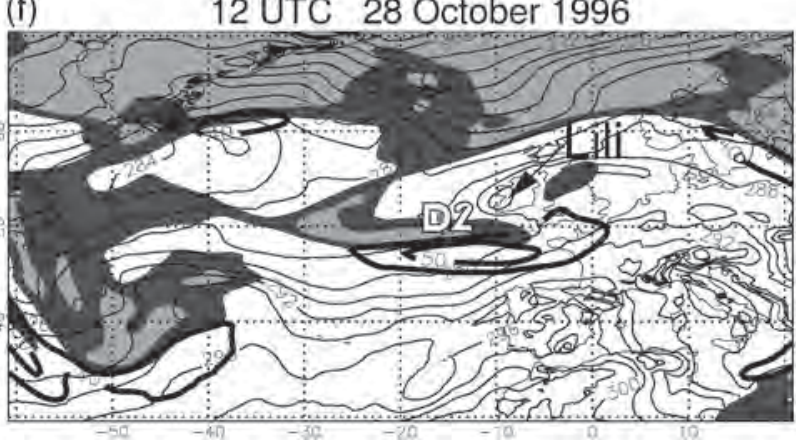

FIG. 1. Met Office analysis fields: 12-hourly from (a) 0000 UTC 26 Oct through (f) 1200 UTC 28 Oct 1996. Gray shading represents isentropic PV on a 325-K surface (lying between 450 and $250 \mathrm{hPa}$ ) with values from 3 to $5 \mathrm{PVU}$ in dark gray and from 5 to $10 \mathrm{PVU}$ in light gray. The solid thick lines highlight the upper-level jet on the $325-\mathrm{K}$ isentropic surface depicted by 40 and $50 \mathrm{~m} \mathrm{~s}{ }^{-1}$ isotachs. Thin solid lines are potential temperature contours (2-K interval) at $900 \mathrm{hPa}$. "D1" and "D2" correspond to the first and second tropopause depression to interact with Lili during the intensification stage.

the second tropopause depression (D2), which emerged from the trough $\mathrm{Tr}$ to the north of the transformed surface cyclone (see Figs. 1 and 2 in Browning et al. 2000). The second tropopause depression (D2) was larger and deeper than D1 and had a major effect on the surface cyclone intensification, leading to a new cloud head in addition to that associated with D1 (Browning et al. 2000; see also Fig. 1e). The low-level circulation was associated with a PV anomaly remnant of the tropical cyclone PV tower at the center of the surface cyclone (not shown) and a warm seclusion extending throughout the troposphere as described by Browning et al. (1998). The two dry intrusions suc- ceeded one another in encircling the warm seclusion at the core of the transformed cyclone (ex-Lili) (Figs. 1e and 1f).

The surface frontal structure of ex-Lili resembled the "T-bone" frontal structure of the Shapiro and Keyser (1990) model with frontal fracture (Browning et al. 1998). The mature cyclone crossed the British Isles during 28 October and its remnants crossed the northern European mainland on the 29th.

\section{Method}

The role of the tropical cyclone in the ET process was determined by comparing forecasts starting from initial 
conditions with and without the tropical cyclone. The forecasts were initialized at 0000 UTC 26 October. The initialization time was chosen before the tropical cyclone started to interact significantly with a trailing cold front to the north of the tropical cyclone but as late as possible in order to obtain a good forecast.

The cyclonic warm-core vortex associated with the tropical cyclone was removed from the initial conditions by applying PV surgery as in Ahmadi-Givi et al. (2004). This method consists of replacing the PV tower associated with the tropical cyclone by the background PV at each vertical level and then applying the PV inversion technique based on Davis and Emanuel (1991) to obtain the balanced fields that satisfy nonlinear balance. The domain of the PV inversion was chosen to be centered on the tropical cyclone without including the upstream upper-level trough. The moisture anomaly associated with the tropical cyclone core was also removed by replacing it with a background value outside the hurricane core (defined using the method given in Agustí-Panareda et al. 2004). ${ }^{1}$

The initial outflow anomaly was not removed because it was a weak anomaly and its removal would have required using a PV inversion domain that would interfere with the upstream upper-level trough. In addition, $\mathrm{PV}$ inversion requires the negative $\mathrm{PV}$ values to be replaced by very small positive PV values, which further weakens the negative PV anomaly. The resulting fields, after removing the cyclonic warm vortex and moisture anomaly collocated with it, were used to initialize the numerical model forecast without the tropical cyclone (NOTC). For consistency the control forecast with the tropical cyclone present in the initial conditions (CNTRL) was also initialized from balanced fields obtained by applying PV inversion to the unmodified PV field.

The numerical model used is the hydrostatic Met Office Unified Model described in Cullen (1993) and used operationally until summer 2002. In this study we used version 4.5 on a limited-area rotated grid with a horizontal resolution of approximately $40 \mathrm{~km}(\Delta x=\Delta y=$ $0.4425^{\circ}$ ) and 38 vertical levels (14 in the boundary layer). The model configuration used for the numerical experiments includes the Gregory and Rowntree (1990) convection scheme with convective available potential energy closure and a mixed-phase precipitation scheme. The model was initialized with European Centre for Medium-Range Weather Forecasts (ECMWF)

\footnotetext{
${ }^{1}$ Sensitivity experiments showed that removing the moisture anomaly associated with the tropical cyclone did not affect the evolution of the forecast for this case study.
}

analysis data $\left(1^{\circ}\right.$ horizontal resolution). ${ }^{2}$ The ECMWF analysis data do not include a tropical cyclone bogus scheme.

\section{Numerical experiments}

Before presenting the results from the numerical experiments, the forecasts of the tracks followed by Lili (Fig. 2) and the evolution of its central MSLP (Fig. 3) are evaluated. The track of Lili in the forecast initialized from balanced fields (CNTRL) was nearly identical to a forecast initialized from analysis fields (FCT). It also followed quite closely the track from the Met Office analyses [which is nearly identical to the National Hurricane Center (NHC) best track], but deviated approximately $500 \mathrm{~km}$ to the southwest at 1200 UTC 27 October. The forecast tracks deviated from the analysis track because of the overestimation during the forecast in the strength of a low pressure system to the northeast of Lili, which affected Lili's track in the forecast. The intensity of Lili was underestimated by $\sim 20$ $\mathrm{hPa}$ in the initial conditions derived from coarseresolution ECMWF global analysis data $\left(1^{\circ}\right.$ horizontal resolution). Given the initial discrepancy between the ECMWF global resolution analysis and the Met Office limited-area model (LAM) analysis $\left(0.5^{\circ}\right.$ horizontal resolution), it is not surprising that there was a bias of $\sim 12 \mathrm{hPa}$ between the forecasts and the Met Office analysis data (Fig. 3). However, the general MSLP evolution and deepening rates in the forecasts were close to those of the analysis data. Initially, the central MSLP from the Met Office analysis was $5 \mathrm{mb}$ weaker than the MSLP from the NHC best-track data (not shown). However, this difference in MSLP became smaller as the ET progressed. Finally, the MSLP evolution of both forecasts (from analysis and balanced fields) was very similar until 1200 UTC 28 October when the surface cyclone in the analysis started to fill. Thus, it is concluded that the experiments described here were not very sensitive to the use of the balanced initial conditions that are a consequence of PV inversion.

The role of Lili in the ET event is described below by comparing the forecasts with and without Lili in the initial conditions. When Lili was removed from the initial conditions no significant extratropical development occurred (Fig. 4). Thus, Lili played a crucial role in the extratropical development that occurred during Lili's ET.

First, Lili triggered warm frontogenesis at low levels

\footnotetext{
${ }^{2}$ The Met Office data required to initialize the model were not available as they were only archived for a limited period of time.
} 


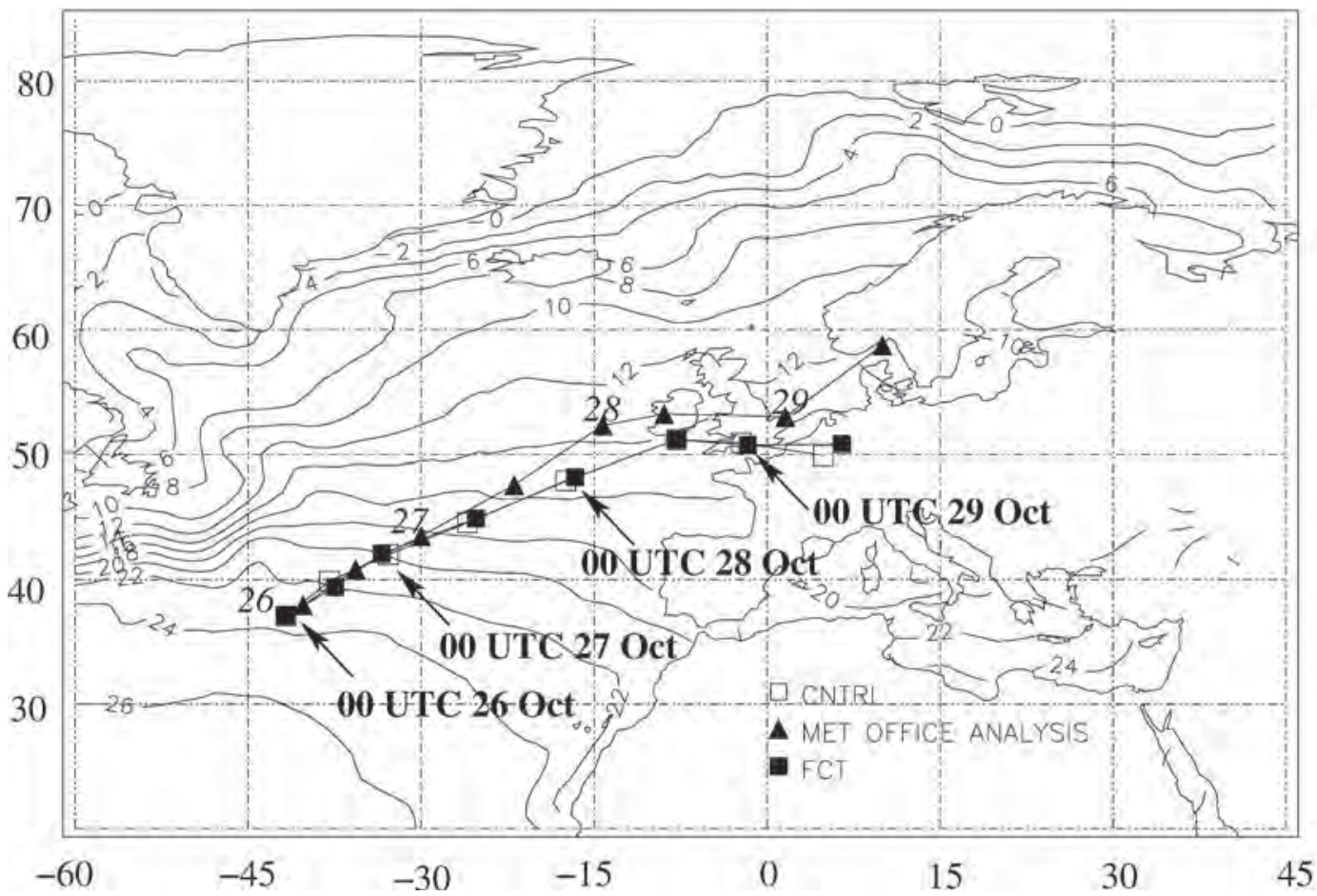

FIG. 2. Track followed by Lili (1996) from Met Office analysis data, forecast from analysis fields (FCT) and the control forecast (CNTRL). Both forecasts were started at 0000 UTC 26 Oct 1996. Data are plotted at 12-hourly intervals. Overlaid contours are mean SSTs for Oct 1996 from the Reynolds dataset (Reynolds and Smith 1994).

along the trailing cold front of a larger low pressure system downstream to the northeast (see L in Figs. 5a and $5 \mathrm{~b}$ ), leading to secondary cyclogenesis around 1200 UTC 26 October (Fig. 5a). The formation of fronts on Lili's northern flank was followed $12 \mathrm{~h}$ later by the generation of a low-level PV band associated with latent heat release along the warm front and the bentback warm front (Fig. 5c), which was not present in the forecast without Lili (Fig. 5d). At 1200 UTC 27 October, the warm front had intensified with a strong gradient of potential temperature at $900 \mathrm{hPa}$ and $\mathrm{PV}$ values between 2 and 3 potential vorticity units (PVU; $1 \times$ $10^{-6} \mathrm{~m}^{2} \mathrm{~s}^{-1} \mathrm{~K} \mathrm{~kg}^{-1}$ ) along the warm front (Fig. 5e). Lili also advected warm/moist air to the south of the British Isles. This can be observed by comparing Figs. $4 \mathrm{a}$ and 4b. Finally and most importantly, the surface low that originated from Lili induced the advection of PV from upper levels, leading to the generation of two tropopause depressions in the control forecast (see D1 and D2 in Figs. 6a, 6c, and 6e) not present in the forecast without Lili (Figs. 6b, 6d, and 6f).

The two tropopause depressions in the control forecast are consistent with those observed in the analysis and reported by Browning et al. (2000). The first tropopause depression (D1) originated from the west (Fig. 6a) and descended down to approximately $400 \mathrm{hPa}$ as it wrapped cyclonically around the center of the surface low at 0000 UTC 28 October (Fig. 6c). The second and larger tropopause depression (D2) originated from a trough to the north of Lili (Fig. 6a). As the trough became thinner (Fig. 6c) the positive PV associated with D2 was cut off from the base of the trough (Fig. 6e). Then D2 merged with D1 as it also wrapped cyclonically around the center of the surface cyclone descending down to $450 \mathrm{hPa}$. These two tropopause depressions interacted with the surface cyclone during the intensification period (from 1200 UTC 27 October to 1200 UTC 28 October) when the surface cyclone deepened $9 \mathrm{hPa}$ in $24 \mathrm{~h}$ (see Fig. 3).

In the forecast without Lili, the evolution of the upper-level trough and its associated positive PV anomaly was very different. The upper-level positive PV anomaly did not wrap up cyclonically but anticyclonically around a high pressure system upstream (around $55^{\circ} \mathrm{N}$ in Figs. $6 \mathrm{~d}$ and $6 \mathrm{f}$ ).

\section{Discussion}

\section{a. Discussion of the numerical experiments}

It is still not clear why some cases of ET result in explosive intensifications and some in just moderate intensifications. The case study of the ET of Lili (1996) 


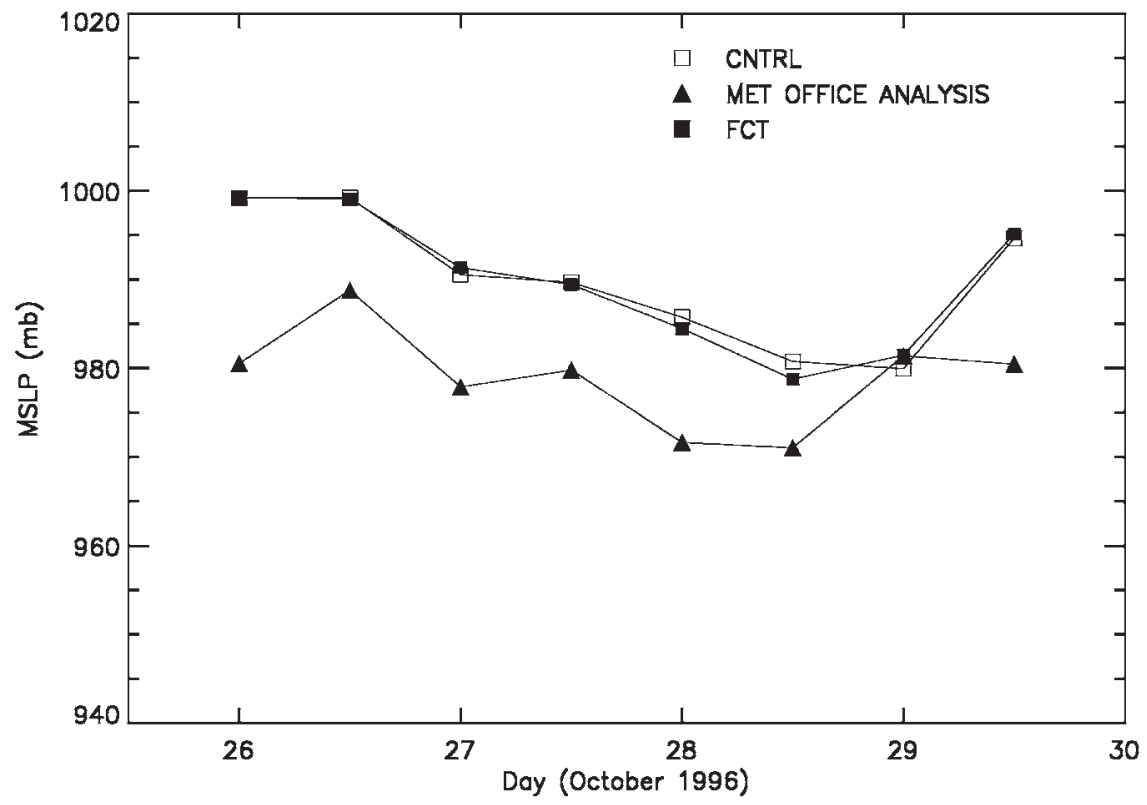

FIG. 3. Minimum mean sea level pressure at the center of Lili from Met Office analysis data, forecast from analysis fields (FCT) and the control forecast (CNTRL). Both forecasts were started at 0000 UTC 26 Oct 1996. Data are plotted at 12-hourly intervals.

presented in this paper follows a moderate intensification. By performing forecasts with and without the tropical cyclone in the initial conditions, it is clear that Lili played a crucial role in the extratropical development. Thus, the results shown in this paper contrast with the results from other case studies in the literature in which the tropical cyclone has been found to play a secondary role (e.g., McTaggart-Cowan et al. 2001; Agustí-Panareda et al. 2004). Indeed, Lili is the first case where the tropical cyclone has been shown to trigger extratropical cyclogenesis in a region that was not conducive to extratropical surface cyclogenesis. The transforming tropical cyclone induced the thinning and cyclonic wrapping-up of the upstream upper-level positive PV anomaly, which caused the surface cyclone to intensify. According to the classification of Klein et al. (2002), the midlatitude circulation would be characterized as neutral and the tropical cyclone contribution as significant, leading to a relatively rapid intensification in the ET of Lili. The results shown in this paper add to the growing list of different ET cases and highlight the large case-to-case variability of ETs. The case-to-case
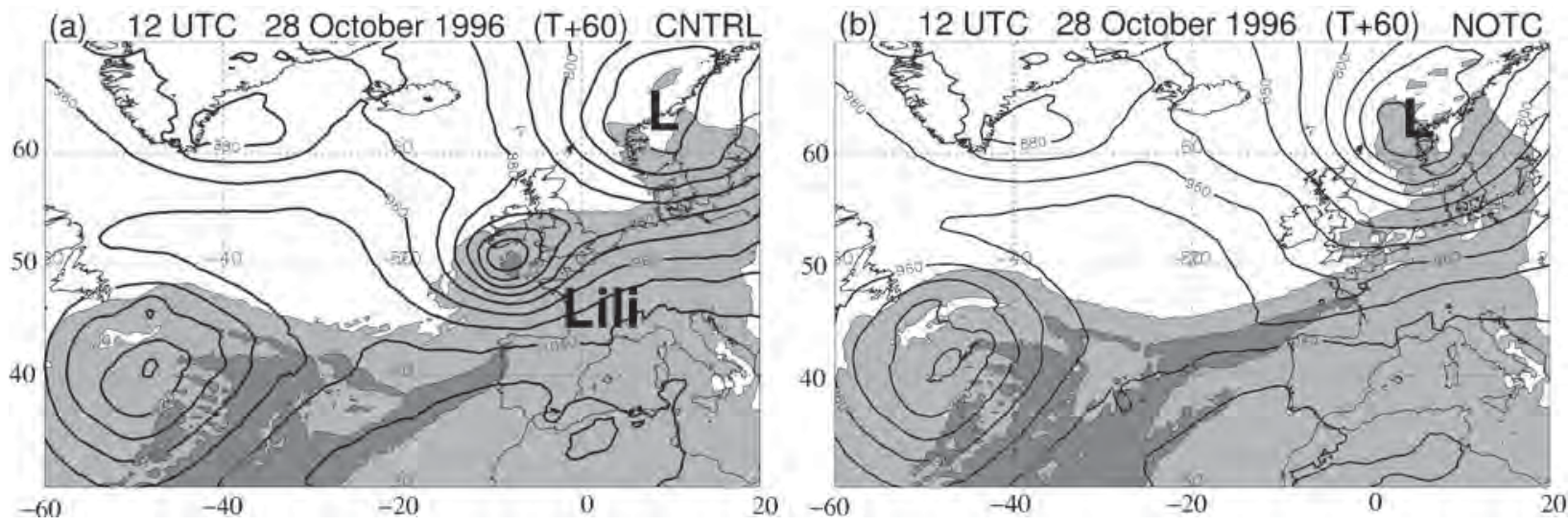

FIG. 4. Equivalent potential temperature field at $900 \mathrm{hPa}$ (white: $260-300 \mathrm{~K}$, light gray: $300-320 \mathrm{~K}$, gray: $320-340 \mathrm{~K}$, and dark gray: 340-360 K) and geopotential height contours at $1000 \mathrm{hPa}$ for (a) the control forecast (CNTRL) and (b) the forecast from initial fields without Lili (NOTC), at 1200 UTC 28 Oct. 
(a) 12 UTC 26 October $1996(T+12)$ CNTRL

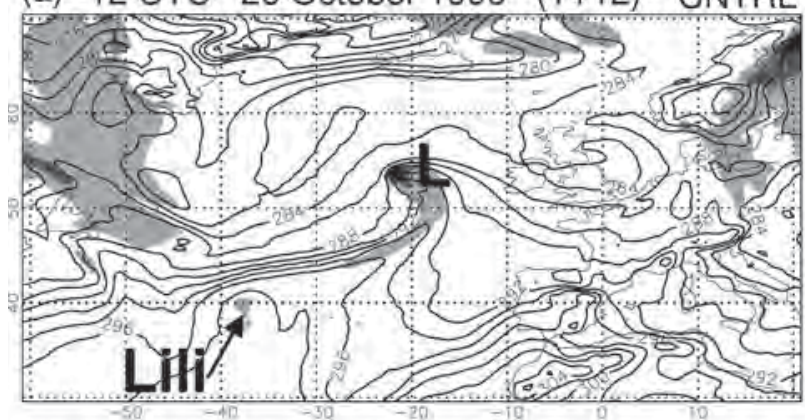

(c) 00 UTC 27 October 1996 (T+24) CNTRL

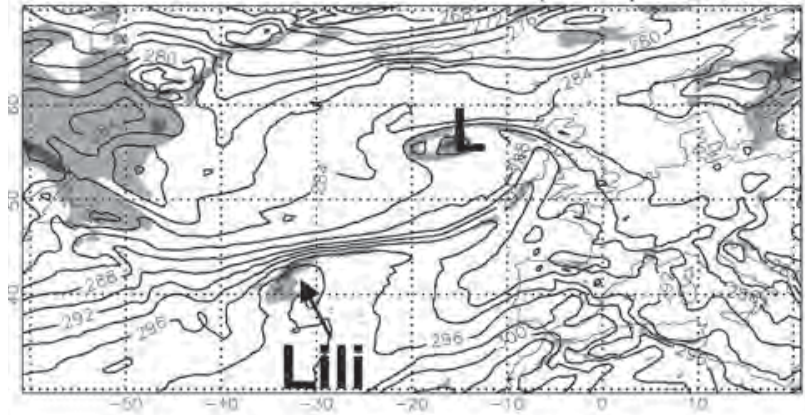

(e) 12 UTC 27 October $1996(T+36)$ CNTRL

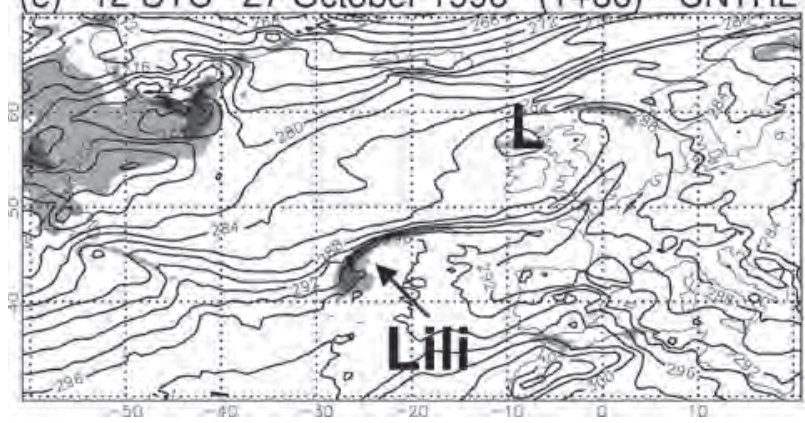

(b) 12 UTC 26 October 1996 ( $T+12)$ NOTC
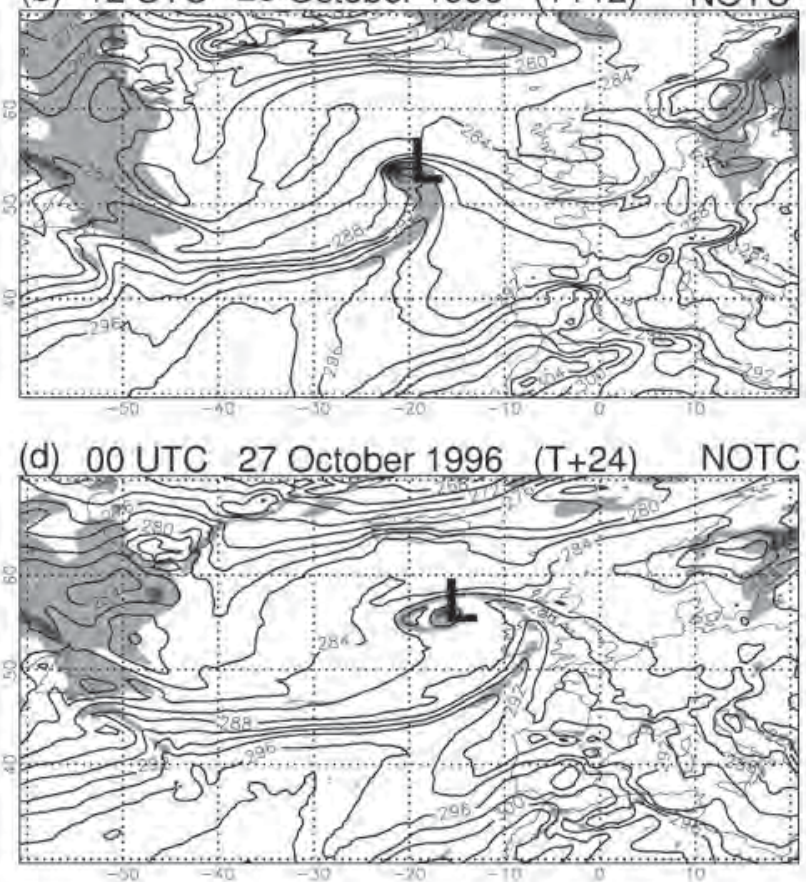

(f) 12 UTC 27 October 1996 (T+36) NOTC

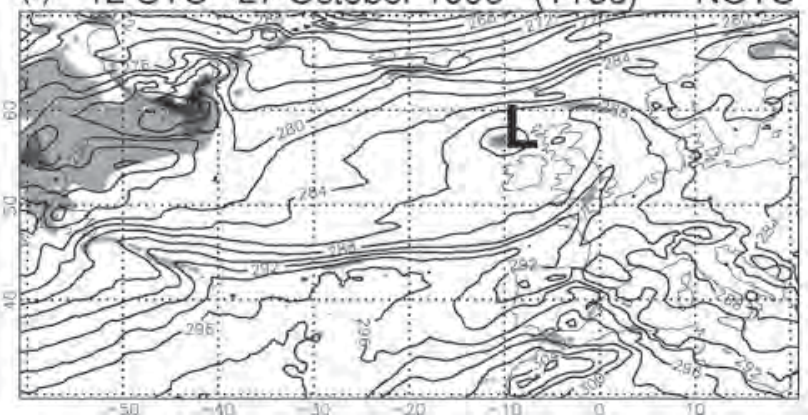

FIG. 5. Potential vorticity (PV) field at $900 \mathrm{hPa}$ (1-2 PVU in light gray, 2-3 PVU in dark gray, and 3-6 PVU in black) and potential temperature contours at $900 \mathrm{hPa}(2-\mathrm{K}$ contour interval) for the (left) control forecast (CNTRL) and (right) forecast from initial fields without Lili (i.e., no PV tower and no moisture anomalies; NOTC).

variability concerns not only the deepening rate of the resulting cyclone but also the relative roles that the midlatitude circulation and the tropical cyclone play in the ET (as highlighted by Klein et al. 2002).

In this paper a possible explanation is proposed for the large case-to-case variability in ETs that is based on the environmental barotropic shear. The environmental barotropic shear can lead to the development of different life cycles of baroclinic cyclones according to idealized experiments (Davies et al. 1991; Thorncroft et al. 1993; Wernli et al. 1998). Shapiro et al. (1999) suggested a link between the idealized life cycles and observations of the evolution of extratropical cyclones. They labeled the life cycles (following Thorncroft et al. 1993) as LC1, LC2, and LC3 depending on whether the barotropic shear is zero, positive (i.e., cyclonic), or negative (i.e., anticyclonic), respectively. Figure 7 shows the link between the large-scale and synoptic structure of the pressure field, the jet streams at upper levels, and the different shears that lead to the different baroclinic life cycles. Note that here the barotropic shear is not relative to the mean zonal jet-as in the idealized experiments of baroclinic life cycles-but to the jet streams that flank planetary waves. LC1 is characterized by a smaller-scale cyclonic wrapping-up near the surface cyclone and a thinning of the upper-level positive PV equatorward of the cyclone. In this case, as the positive PV anomaly evolves, part of it enters a region of anticyclonic shear equatorward of the jets and part of it remains in the region of cyclonic shear pole- 


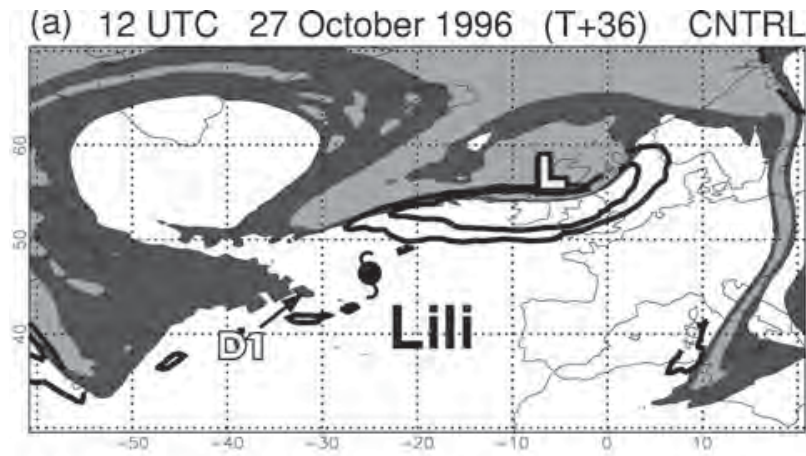

(b) 12 UTC 27 October $1996(T+36) \quad$ NOTC

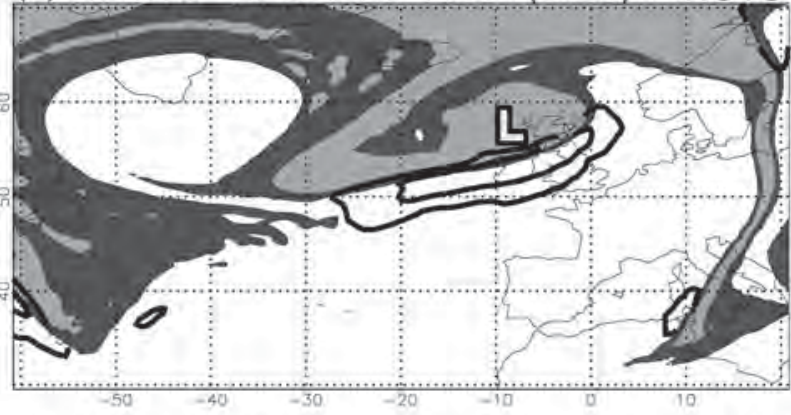

(c) 00 UTC 28 October $1996(T+48)$ CNTRL

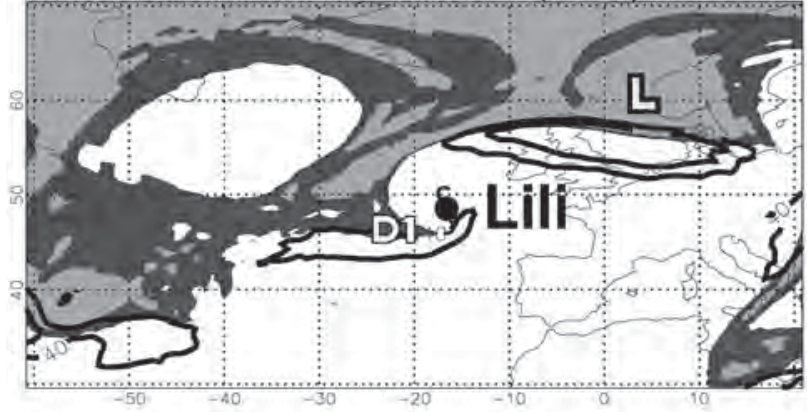

(d) 00 UTC 28 October $1996 \quad(T+48) \quad$ NOTC
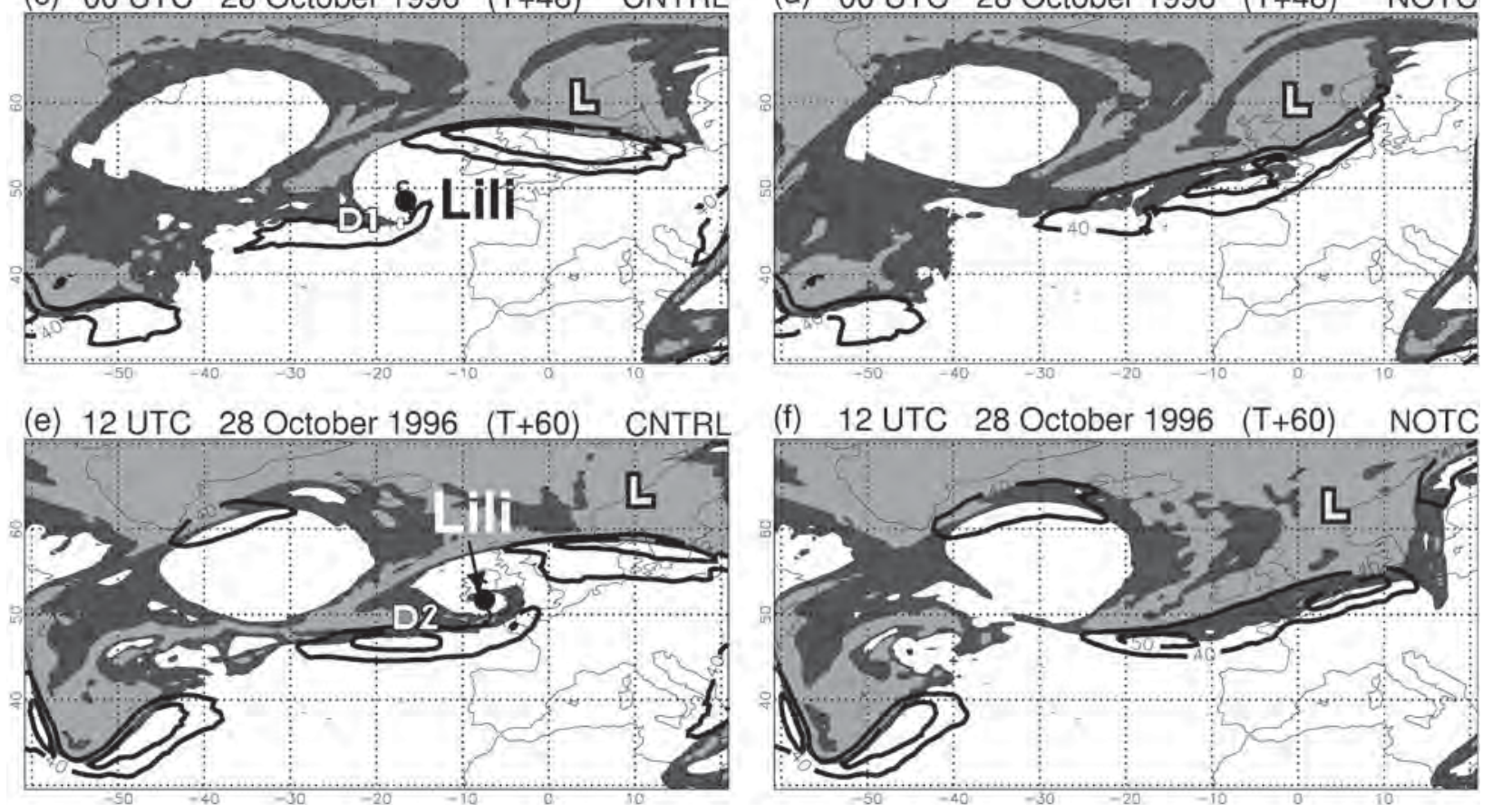

FIG. 6. Horizontal cross sections of isentropic PV and the upper-level jet on a 325-K surface (lying between 450 and $250 \mathrm{hPa}$ ) for the (left) control forecast and (right) forecast from initial fields without Lili (experiment NOTC). Shading denotes PV: dark gray from 3 to 5 PVU and light gray from 5 to 10 PVU. Thick contours are the 40 and $50 \mathrm{~m} \mathrm{~s}^{-1}$ isotachs of the upper-level jet on the 325 -K surface. The location of the surface cyclone associated with Lili is indicated with a "hurricane" symbol, and the downstream surface cyclone with an "L"; "D1" and "D2" correspond to the first and second tropopause depression to interact with Lili during the intensification stage.

ward of the jets. LC2 is characterized by a cyclonic wrapping-up of the upper-level PV anomaly and results in broad and deep surface cyclones (Thorncroft et al. 1993). In this case, the positive PV anomaly remains on the poleward side of the jets throughout the life cycle. Finally, LC3 is characterized by a dramatic thinning and elongation of the upper-level positive PV anomaly with an insignificant surface cyclonic development along a surface cold front. In this case, the positive PV anomaly is located equatorward of the strongest jet to the north.

The results presented in this paper show that the ET of Lili (1996) was different from the ET of Irene (1999)
(Agustí-Panareda et al. 2004). The main difference seems to lie in the nature of the upper-level troughs and their positive PV anomalies, which evolved completely differently for the two case studies. This was not directly evident from the analyses, since both upper-level positive PV anomalies wrapped up cyclonically around the center of the surface cyclone as LC1- and LC2-type developments, respectively (cf. Fig. 6e with LC1 in Fig. 7 and Fig. 5f in Agustí-Panareda et al. (2004) with LC2 in Fig. 7). The difference was clear when the tropical cyclones were removed from the initial conditions. In the case of Irene, the upper-level positive PV anomaly still evolved in an LC2-type life cycle wrapping up cy- 


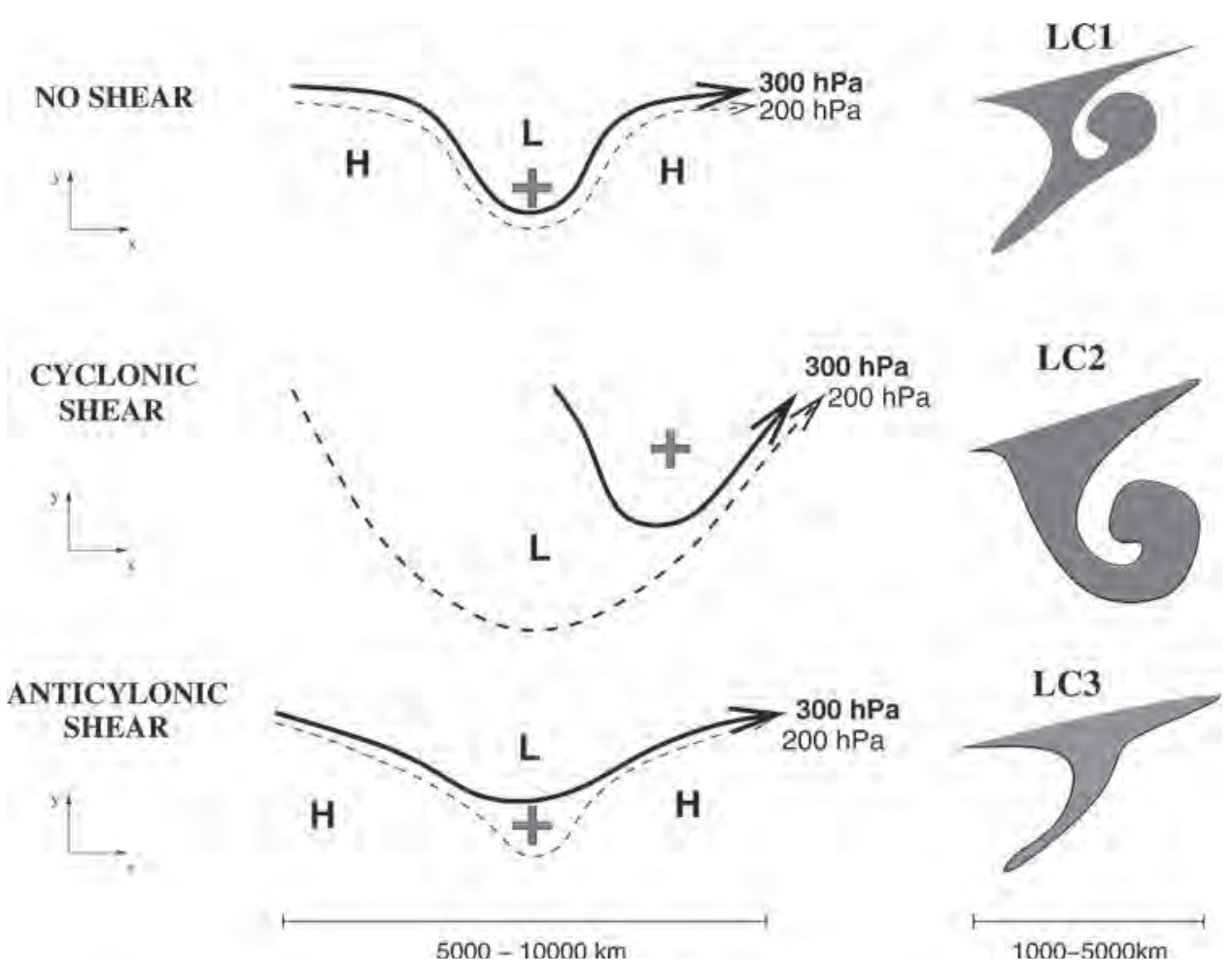

FIG. 7. Schematic showing the planetary wave environment and the mature stage of different baroclinic life cycles at upper levels, based on results and figures from Davies et al. (1991) and Shapiro et al. (1999). (left) The relative position of the $300-\mathrm{mb}$ planetary wave and polar jet stream (solid line with arrow) and the 200-mb planetary wave and subtropical jet stream (dashed line with arrow). The low and high pressure centers associated with the planetary waves in the upper troposphere are indicated by $\mathrm{L}$ and $\mathrm{H}$, respectively. The "+" sign indicates the location of the center of the positive PV anomaly at upper levels. The barotropic shear that the positive PV anomaly experiences is given by the relative position and strength of the jet streams associated with the planetary waves (see text for a more detailed explanation). (right) The final shape that the positive PV anomaly at upper levels (between 200 and 300 $\mathrm{hPa}$ ) evolves into at the end of the baroclinic life cycle labeled as LC1, LC2, and LC3 when there is no barotropic shear, cyclonic shear, or anticyclonic shear, respectively. Gray shading depicts PV values greater than 2 PVU, and the surrounding black line is the 2-PVU contour. The typical ranges of horizontal scales are shown by the horizontal bars at the bottom of the figure.

clonically [see Fig. 16f in Agustí-Panareda et al. (2004) and LC2 in Fig. 7]. However, in the case of Lili, the upper-level positive PV anomaly evolved very differently, as an LC3-type life cycle wrapping up toward a large-scale anticyclone upstream (see Fig. of and LC3 in Fig. 7). These two different upper-level developments (LC2 and LC3) in the extratropical environment in which Irene and Lili entered can be associated with cyclonic and anticyclonic large-scale barotropic shears (as shown in Fig. 7). They resulted in strong and very weak surface developments respectively, which is consistent with results from Wernli et al. (1998) and Shapiro et al. (1999).

The surface frontal development in the ET of Lili corresponds to the Shapiro and Keyser (1990) model, and in the ET of Irene to the Norwegian model (Bjerknes and Solberg 1922; Bergeron 1928). This is also consistent with Wernli et al. (1998). They linked the frontal structure of LC1 to the Shapiro and Keyser model with a "T-bone" frontal structure and the frontal structure of LC2 with the Norwegian conceptual model with the frontal occlusion. Confluence and diffluence has also been shown to affect the evolution of surface frontal cyclone structure, leading to the Shapiro and Keyser model and the Norwegian model, respectively (Schultz et al. 1998). As confluence and diffluence are present at the upper-level jet entrance and exit respectively, these could provide a convenient way to distinguish between the different scenarios. LC1-type developments are expected to be found in the confluence region of an upper-level jet, LC2-type developments in a diffluence region, and LC3-type developments in a region without confluence or diffluence.

The idealized numerical experiments of Ritchie and 


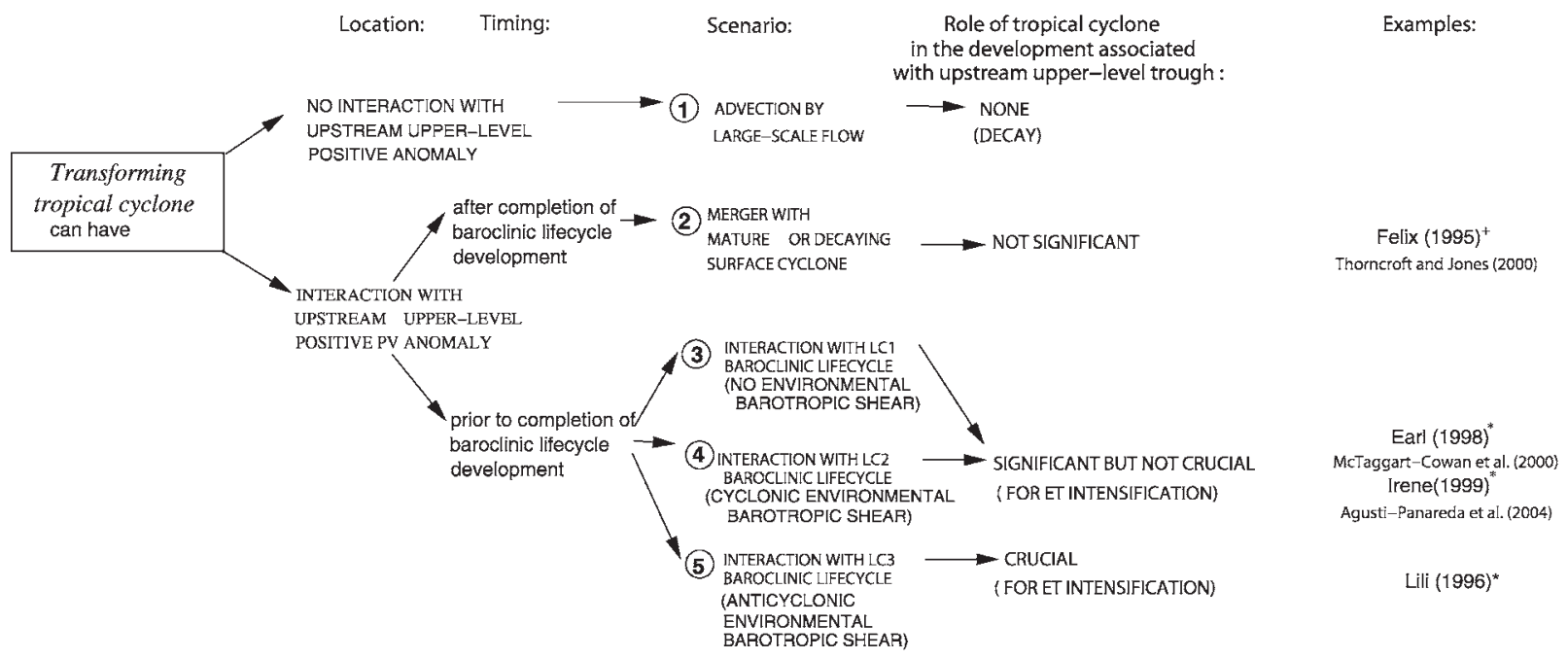

FIG. 8. Schematic showing a hypothesis of possible scenarios for the intensification stage of a transformed tropical cyclone. Examples of the different scenarios are given by a few specific case studies. The case studies that have been tested by removing the tropical cyclone from the initial conditions in numerical experiments (based on PV inversion) are marked with an asterisk. The case studies that have not been tested and are based on synoptic analyses are marked with a cross. See text for detailed explanation.

Elsberry (2003) have also shown the crucial role of a tropical cyclone during the reintensification period of an ET when the upstream upper-level trough is weak. Ritchie and Elsberry (2003) define a weak trough perturbation as a positive PV anomaly with associated maximum winds of $15 \mathrm{~m} \mathrm{~s}^{-1}$ superimposed on the environmental flow. Classifying troughs according to their strength in terms of maximum winds can be subjective partly because the maximum wind strength can vary throughout their lifetime. In this paper we are mainly interested to know whether or not the upper-level trough would develop without the tropical cyclone. Therefore, the classification of the baroclinic life cycles followed by the trough can be a more useful tool to distinguish between upper-level troughs that will lead to significant development or not, rather than the initial maximum winds associated with the upper-level positive PV anomaly.

\section{b. The role of the transformed tropical cyclone in the intensification during ET: A hypothesis}

To improve our understanding of the large case-tocase variability in the ETs of tropical cyclones, we propose a classification of ET scenarios by linking the role of a tropical cyclone in the upstream development and the environmental barotropic shear. This is supported by results from previously analyzed different case studies in the literature. We also speculate on what the role of the tropical cyclone would be for scenarios that have not yet been tested.

Several conceptual models for ETs have been pro- posed by previous studies that concentrate on different aspects involved in the ET process. Matano and Sekioka (1971) proposed a conceptual model based on case studies in the northwest Pacific by focusing on the surface interactions of a tropical cyclone with either a preexisting baroclinic zone, a preexisting extratropical cyclone, or polar air with weak/strong outbreak of cold air. Klein et al. (2000) concentrated on the initial stage of the ET where the tropical cyclone transforms as it interacts with a preexisting baroclinic zone. Other conceptual models have been proposed for different basins (e.g., Sinclair 2002; Foley and Hanstrum 1994). Here we concentrate on the extratropical stage, after the transformation stage, when the tropical cyclone has already developed asymmetries by interacting with the baroclinic zone. During the extratropical stage some transitioning tropical cyclones intensify and some do not. Harr and Elsberry (2000) distinguished two types of midlatitude circulation patterns in the northwest Pacific that can affect the timing of the intensification in the ET. Klein et al. (2002) linked the outcome of the intensification to whether the upstream extratropical forcing was favorable and the tropical cyclone was in phase with this extratropical forcing. The key question addressed here is, how crucial is the role of the tropical cyclone for different possible scenarios?

Figure 8 summarizes the possible scenarios by linking together different factors to the role of the transitioning tropical cyclone in the extratropical development. The first factor considered here is the interaction with an upstream upper-level positive PV anomaly associated 
with an upper-level trough. The relative positions of the upper-level positive PV anomaly and the transformed surface cyclone will determine whether the interaction is significant or not (see Klein et al. 2002). Here we only consider the extreme cases in which the interaction between the transforming cyclone and the upper-level trough is either nonexistent or significant. In the case where there is no interaction with the upper-level positive PV anomaly upstream-because there is no suitably located upper-level positive PV anomaly upstream-the transformed surface cyclone will decay as it is advected downstream subject to the large-scale flow. This would correspond to scenario 1 in Fig. 8 and it would be equivalent to the "Decayers" scenario of Klein et al. (2002) where there is no tropical cyclone contribution.

When there is an interaction with a preexisting upper-level positive PV anomaly to the west of the cyclone, different outcomes might occur depending on the time of interaction between the transitioning tropical cyclone and the upper-level positive PV anomaly upstream. If the transformed tropical cyclone interacts with the upstream trough after its associated upperlevel positive PV anomaly has reached the end of its baroclinic life cycle, then the transitioning cyclone is expected to merge with a broad quasi-barotropic mature low upstream, as in the ET of Felix (1995) (Thorncroft and Jones 2000). This corresponds to scenario 2 in Fig. 8. The role of the tropical cyclone is not significant, as the intensity of the resulting cyclone is not significantly affected by the merging of the vortices.

If the upstream upper-level positive PV anomaly is at the beginning of its baroclinic life cycle then there will be an active interaction between the transitioning surface cyclone and the upper-level positive PV anomaly, resulting in intensification. The role of the tropical cyclone can vary, and in this section a hypothesis is proposed based on the environmental barotropic shear that is associated with different baroclinic life cycles. For example, the case study of Lili presented in this paper suggests that LC3 life cycles cannot produce intensification during an ET unless a tropical cyclone is able to induce a tropopause depression leading to baroclinic instability. The tropical cyclone in this case is crucial for the reintensification of the transforming cyclone (see scenario 5 in Fig. 8). On the other hand, the ETs of Earl (1998) and Irene (1999) were classified as LC2 developments with explosive deepening regardless of the presence of the tropical cyclone (see McTaggartCowan et al. 2001 and Agustí-Panareda et al. 2004, respectively). Thus in an environment with cyclonic barotropic shear supporting LC2-type developments, the role of the tropical cyclone is not thought to be crucial, although it can still be significant (see scenario 4 in Fig. 8). Agustí-Panareda et al. (2004) showed that the outflow of transitioning Irene (1999) played a role in delaying the reintentensification period and enhancing the deepening rate of the transitioning cyclone as well as having a strong impact on the extratropical development downstream. Finally, LC1 life cycles still need to be explored. Given that LC1 life cycles can lead to development of intense cyclones, we speculate that a transforming tropical cyclone interacting with such a development would also have a secondary role in the ET, that is to say, a significant but not crucial role (see scenario 3 in Fig. 8). We would also expect that the ET would have the potential for explosive reintensification.

The ET scenarios presented in Fig. 8 that relate the different baroclinic life cycles to the role of the tropical cyclone in the development upstream and its potential for intensification are only based on few case studies. In addition, there may be other factors that can affect the role of the tropical cyclone during an ET that have not been considered here (e.g., the intensity and scale of the tropical cyclone and upper-level PV anomaly, the advection of moisture by the transitioning tropical cyclone). Thus, Fig. 8 is still preliminary, but it has the potential to be revised, as all possible factors contributing to the role of the tropical cyclone in the ET and the different possible ET scenarios proposed here are tested by performing additional case studies and possibly idealized numerical experiments. This is particularly important for LC1 life cycles, which have not yet been explored.

\section{Summary}

By removing the tropical cyclone in model runs, it has been found that Lili played a crucial role in the extratropical development during its ET. To explain this outcome, the type of upper-level development supported by the extratropical environment has been examined, that is to say, the development that would have occurred in the absence of the tropical cyclone. This has been characterized in terms of baroclinic life cycles that depend on the large-scale barotropic shear. We have hypothesized that there could be a link between the role of the tropical cyclone in the extratropical development and the large-scale barotropic shear of the extratropical environment that leads to different baroclinic life cycles. If this is the case, the barotropic shear in the region of the jet could be used to explain part of the large case-to-case variability that exists in ET events.

Acknowledgments. Thanks to Peter Panagi and Chang Wang for providing the analysis data and soft- 
ware, and to Sarah Jones, Keith Browning, Julia Slingo, and Brian Hoskins for their comments and discussions. We are grateful for the comments of David Schultz and three anonymous referees. Funding for this research was provided by a NERC studentship.

\section{REFERENCES}

Agustí-Panareda, A., C. D. Thorncroft, G. C. Craig, and S. L. Gray, 2004: The extratropical transition of Hurricane Irene (1999): A potential vorticity perspective. Quart. J. Roy. Meteor. Soc., 130, 1047-1074.

Ahmadi-Givi, F., G. C. Craig, and R. S. Plant, 2004: The dynamics of a mid-latitude cyclone with very strong latent heat release. Quart. J. Roy. Meteor. Soc., 130, 295-323.

Bergeron, T., 1928: Über die dreidimensional verknüpfende. Wetteranalyse. Geofys. Publ., 5, 1-111.

Bjerknes, J., and H. Solberg, 1922: Life cycle of cyclones and the polar front theory of atmospheric circulation. Geofys. Publ., $\mathbf{3}, 1-18$.

Bosart, L. F., and G. M. Lackmann, 1995: Postlandfall tropical cyclone re-intensification in a weakly baroclinic environment: A case study of Hurricane David (September 1979). Mon. Wea. Rev., 123, 3268-3291.

Browning, K. A., G. Vaughan, and P. Panagi, 1998: Analysis of an ex-tropical cyclone after its re-intensification as a warm-core extratropical cyclone. Quart. J. Roy. Meteor. Soc., 124, 2329 2356.

— A. J. Thorpe, A. Montani, D. Parsons, M. Griffiths, P. Panagi, and E. M. Dicks, 2000: Interactions of tropopause depressions with an ex-tropical cyclone and sensitivity of forecasts to analysis errors. Mon. Wea. Rev., 128, 2734-2755.

Carroll, E. B., 1997: Poorly forecast trough disruption shown in water vapour images. Meteor. Appl., 4, 229-234.

Cullen, M. J. P., 1993: The unified forecast/climate model. Meteor. Mag., 122, 81-93.

Davies, H. C., C. Schär, and H. Wernli, 1991: The palette of fronts and cyclones within a baroclinic wave development. J. Atmos. Sci., 48, 1666-1689.

Davis, C. A., and K. A. Emanuel, 1991: Potential vorticity diagnostics of cyclogenesis. Mon. Wea. Rev., 119, 1929-1953.

DiMego, G. J., and L. F. Bosart, 1982a: Transformation of Tropical Storm Agnes into an extratropical cyclone. Part I: The observed fields and vertical motion computations. Mon. Wea. Rev., 110, 385-411.

_, and — 1982b: Transformation of Tropical Storm Agnes into an extratropical cyclone. Part II: Moisture, vorticity and kinetic energy budgets. Mon. Wea. Rev., 110, 412-433.

Evans, J. L., and R. E. Hart, 2003: Objective indicators of the life cycle evolution of extratropical transition for Atlantic tropical cyclones. Mon. Wea. Rev., 131, 909-925.

Foley, G. R., and B. N. Hanstrum, 1994: The capture of tropical cyclones by cold fronts off the coast of Australia. Wea. Forecasting, 9, 577-592.

Gregory, D., and P. R. Rowntree, 1990: A mass flux convection scheme with representation of cloud ensemble characteristics and stability-dependent closure. Mon. Wea. Rev., 118, 14831506.

Harr, P. A., and R. L. Elsberry, 2000: Extratropical transition of tropical cyclones over the western North Pacific. Part I: Evo- lution of structural characteristics during the transition process. Mon. Wea. Rev., 128, 2613-2633.

Hart, R. E., and J. L. Evans, 2001: A climatology of the extratropical transition of Atlantic tropical cyclones. J. Climate, 14, $546-564$.

Jones, S. C., and Coauthors, 2003: The extratropical transition of tropical cyclones: Forecast challanges, current understanding and future directions. Wea. Forecasting, 18, 1052-1092.

Klein, P. M., P. A. Harr, and R. L. Elsberry, 2000: Extratropical transition of western North Pacific tropical cyclones: An overview and conceptual model of the transformation stage. Wea. Forecasting, 15, 373-395.

- — - and — 2002: Extratropical transition of western North Pacific tropical cyclones: Midlatitude and tropical cyclone contributions to reintensification. Mon. Wea. Rev., 130, 2240-2259.

Lawrence, M. B., cited 1996: Preliminary report on Hurricane Lili, 14-27 October 1996. [Available online at http://www.nhc. noaa.gov/1996lili_text.html.]

Matano, H., and M. Sekioka, 1971: Some aspects of extratropical transformation of a tropical cyclone. J. Meteor. Soc. Japan, 49, 736-743.

McTaggart-Cowan, R., J. R. Gyakum, and M. K. Yau, 2001: Sensitivity testing of extratropical transitions using potential vorticity inversions to modify initial conditions: Hurricane Earl case study. Mon. Wea. Rev., 129, 1617-1636.

Reynolds, R. W., and T. M. Smith, 1994: Improved global sea surface temperature analyses using optimum interpolation. $J$. Climate, 7, 929-948.

Ritchie, E. A., and R. L. Elsberry, 2003: Simulations of the extratropical transition of tropical cyclones: Contributions by the midlatitude upper-level trough to reintensification. Mon. Wea. Rev., 131, 2112-2128.

Schultz, D. M., D. Keyser, and L. F. Bosart, 1998: The effect of large-scale flow on low-level frontal structure and evolution in midlatitude cyclones. Mon. Wea. Rev., 126, 1767-1791.

Shapiro, M. A., and D. Keyser, 1990: Fronts, jets and the tropopause. Extratropical Cyclones: The Erik Palmén Memorial Volume, C. W. Newton and E. O. Holopainen, Eds., Amer. Meteor. Soc., 167-191.

— , and Coauthors, 1999: A planetary-scale to mesoscale perspective of the life cycles of extratropical cyclones: The bridge between theory and observations. The Life Cycles of Extratropical Cyclones, M. A. Shapiro and S. Grönås, Eds., Amer. Meteor. Soc., 39-185.

Sinclair, M. R., 1993: Synoptic-scale diagnosis of the extratropical transition of a southwest Pacific tropical cyclone. Mon. Wea. Rev., 121, 941-960.

_ 2002: Extratropical transition of southwest Pacific tropical cyclones. Part I: Climatology and mean structure changes. Mon. Wea. Rev., 130, 590-609.

Thorncroft, C. D., and S. C. Jones, 2000: The extratropical transitions of Hurricanes Felix and Iris in 1995. Mon. Wea. Rev., 128, 947-972.

- B. J. Hoskins, and M. E. McIntyre, 1993: Two paradigms of baroclinic-wave life-cycle behaviour. Quart. J. Roy. Meteor. Soc., 119, 17-55.

Wernli, H., R. Fehlmann, and D. Lüthi, 1998: The effect of barotropic shear on upper-level induced cyclogenesis: Semigeostrophic and primitive equation numerical simultions. J. Atmos. Sci., 55, 2080-2094. 